\title{
René Maran et les écrivains haïtiens
}

Éloges de Jacques Roumain et Edris Saint-Amand

Yves Chemla

\section{(2) OpenEdition}

1 Journals

Édition électronique

URL : https://journals.openedition.org/coma/7763

DOI : 10.4000/coma.7763

ISSN : 2275-1742

Éditeur

Institut des textes \& manuscrits modernes (ITEM)

\section{Référence électronique}

Yves Chemla, « René Maran et les écrivains haïtiens », Continents manuscrits [En ligne], 17 | 2021, mis en ligne le 13 octobre 2021, consulté le 12 janvier 2023. URL : http://journals.openedition.org/coma/ 7763 ; DOI : https://doi.org/10.4000/coma.7763

Ce document a été généré automatiquement le 12 janvier 2023.

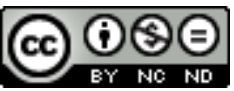

Creative Commons - Attribution - Pas d'Utilisation Commerciale - Pas de Modification 4.0 International - CC BY-NC-ND 4.0

https://creativecommons.org/licenses/by-nc-nd/4.0/ 


\title{
René Maran et les écrivains haïtiens
}

\author{
Éloges de Jacques Roumain et Edris Saint-Amand
}

\author{
Yves Chemla
}

Voici quelques phrases que Maran avait rédigées lors de la publication en France de deux romans haïtiens majeurs : Gouverneurs de la rosée (1946, Éditeurs Français Réunis) de Jacques Roumain; Bon Dieu rit (1952, Domat) d'Edris Saint-Amand (ces documents conservés à la bibliothèque universitaire de l'université Cheikh Anta Diop de Dakar sont accessibles via le site internet de la BU).

Pour le premier, Maran développe une longue reformulation de l'œuvre d'un écrivain dont il reconnaît en même temps ne pas bien connaître l'œuvre antérieure au roman posthume, qu'il reconnaît comme étant un chef d'œuvre.

\begin{abstract}
La plus belle joie que puisse avoir un écrivain est celle qu'il tire soudain de la certitude d'avoir découvert un grand livre. Je dois à Gouverneurs de la rosée d'avoir éprouvé cette joie-là. Depuis lors, je regrette que le hasard ne m'ait jamais mis autrefois en présence de l'auteur de ce roman où la virilité de la pensée s'allie à l'émotion de la qualité la plus secrète.
\end{abstract}

Dans son article de 1952, Maran revient encore sur le roman «du sol et de l'eau » et considère Roumain comme un des écrivains les plus importants de la Caraïbe ${ }^{1}$. Les Cuvres complètes de Roumain ${ }^{2}$ ne mentionnent guère Maran, sinon dans un éloge de La Montagne ensorcelée (1931), souvent considéré comme les prolégomènes à Gouverneurs de la rosée, écrit par Louis Diaquoi (1909-1932), journaliste et essayiste nationaliste, proche de François Duvalier et Lorimer Denis. La Montagne ensorcelée est un « livre qui rappelle par la forme, on dirait aussi par le fond Batouala de René Maran ${ }^{3}$ ». Puis plus rien, sinon dans des références bibliographiques qui associent les deux écrivains. Mais on peut aisément supposer que Roumain connaît l'œuvre de Maran et Maran lui-même.

4 La référence au roman de Saint-Amand est piquante : Maran rapproche les deux textes en raison du travail sur la langue des deux auteurs et des thématiques paysannes.

On retrouve, dans Bon Dieu rit, le romain haïtien que M. Edris Saint-Amand, écrivain haïtien, vient de publier, aux éditions Domat, exactement les mêmes 
thèmes que feu M. Jacques Roumain a développés dans ses Gouverneurs de la Rosée.

Or les œuvres sont plutôt dissemblables. Saint-Amand avait conçu son roman comme l'inverse critique de celui de Roumain, comme le refus même de la posture héroïque et tragique relativement commune dans le roman de tradition haïtienne. Henri Micciollo et Didier Maule ont traité de cette question, que plusieurs conversations privées avec Edris Saint-Amand (entre 1982 et 1984) ont confirmée ${ }^{4}$.

Les deux manuscrits sont mentionnés par Florence Martin dans «René Maran lecteur $»^{5}$.

\section{NOTES}

1. René MARAN, « Le mouvement littéraire aux Antilles et à la Guyane », De West-Indische Gids, vol. 33, KITLV, Royal Netherlands Institute of Southeast Asian and Caribbean Studies, Brill], 1952, pp. 12-22, http://www.jstor.org/stable/41848743. Comme on l'a signalé plus haut, Saint-Amand publie son roman précisément en 1952.

2. Jacques Roumain, Euvres complètes, sous la coordination de Léon-François Hoffmann et Yves Chemla, Paris, CNRS Éditions, 2018.

3. Ibid., p. 1185.

4. Henri micciollo, «Modernité dans Bon Dieu rit»; Didier MAUle, «À propos de Bon Dieu rit. L'Espace d'un roman ", Conjonction, Revue franco-haïtienne, Institut français d'Haïti, $\mathrm{n}^{\circ} 157$, mars 1983 ; p. 13-20 \& 21-45.

5. Florence MARTIN, «René Maran lecteur ", dans Claude Julien (dir.), Regards croisés sur les AfroAméricains, Mélange en l'honneur de Michel Fabre, Tours, Presses universitaires François-Rabelais, coll. « GRAAT 27 », 2003, p. 277-291, disponible sur Internet : http://books.openedition.org/pufr/ 4199.ISBN:9782869064690. DOI : https://doi.org/10.4000/books.pufr.4199.

\section{RÉSUMÉS}

René Maran salue la publication en France de deux romans haïtiens majeurs : Gouverneurs de la rosée (1946, Éditeurs Français Réunis) de Jacques Roumain; Bon Dieu rit (1952, Domat) d’Edris Saint-Amand.

René Maran welcomes the publication in France of two major Haitian novels: Gouverneurs de la rosée (1946, Éditeurs Français Réunis) by Jacques Roumain; Bon Dieu rit (1952, Domat) by Edris Saint-Amand. 
INDEX

Mots-clés : Jacques Roumain, Edris Saint-Amand, René Maran

Keywords : Jacques Roumain, Edris Saint-Amand, René Maran

\section{AUTEUR}

\section{YVES CHEMLA}

Yves Chemla est critique littéraire et docteur de l'Université de La Sorbonne. Il publie des articles consacrés à la littérature haïtienne et aux littératures du Sud. Il enseigne les techniques d'expression à l'Université Paris Descartes et a mené des interventions dans diverses institutions d'enseignement supérieur (Université Saint-Joseph de Beyrouth, École Normale Supérieure et Université d'État d'Haïti, Faculté des études romanes de Varsovie, Université Jagellon de Cracovie). En 2018, il est invité à l'Université de Parme, pour enseigner la littérature haïtienne contemporaine. Il est membre de l'équipe Manuscrits Francophones de l'Institut des Textes et Manuscrits modernes (CNRS-ENS). Il préside l'association île en île qui fête ses 20 ans en 2018 (https://www.gofundme.com/deja-20-ans) et dont l'objet est de faciliter la gestion du site www.ile-en-ile.org, la base de données qui répertorie les littératures francophones des îles. 